\title{
A brown-world cascade in the dung decomposer food web of an alpine meadow: effects of predator interactions and warming
}

\author{
Xinwei Wu, ${ }^{1}$ J. Emmett Duffy, ${ }^{2}$ Peter B. Reich, ${ }^{3}$ And Shucun Sun ${ }^{1,4,5}$ \\ ${ }^{1}$ ECORES Lab, Chengdu Institute of Biology, Chinese Academy of Sciences, Chengdu 610041 China \\ ${ }^{2}$ Virginia Institute of Marine Science, College of William and Mary, Gloucester Point, Virginia 23062-1346 USA \\ ${ }^{3}$ Department of Forest Resources, University of Minnesota, 1530 Cleveland Ave. North, Saint Paul, Minnesota 55108 USA \\ ${ }^{4}$ Department of Biology, School of Life Sciences, Nanjing University, Nanjing 210093 China
}

\begin{abstract}
Top-down control has been extensively documented in food webs based on living plants, where predator limitation of herbivores can cascade to facilitate plant growth (the green-world hypothesis), particularly in grasslands and aquatic systems. Yet the ecosystem role of predators in detrital food webs is less explored, as is the potential effect of climate warming on detritus-based communities. We here show that predators have a "brown-world" role in decomposer communities via a cascading top-down control on plant growth, based on the results of an experiment that factorially manipulated presence and size of two predator species as well as temperature (warmed vs. unwarmed). The inclusion of predatory beetles significantly decreased abundance of coprophagous beetles and thus the rate of dung decomposition and productivity of plants growing surrounding the dung. Moreover, the magnitude of these decreases differed between predator species and, for dung loss, was temperature dependent. At ambient temperature, the larger predators tended to more strongly influence the dung loss rate than did the smaller predators; when both predators were present, the dung loss rate was higher relative to the treatments with the smaller predators but comparable to those with the larger ones, suggesting an antagonistic effect of predator interaction. However, warming substantially reduced dung decomposition rates and eliminated the effects of predation on dung decomposition. Although warming substantially decreased dung loss rates, warming only modestly reduced primary productivity. Consistent with these results, a second experiment exploring the influence of the two predator species and warming on dung loss over time revealed that predatory beetles significantly decreased the abundance of coprophagous beetles, which was positively correlated with dung loss rates. Moreover, experimental warming decreased the water content of dung and hence the survival of coprophagous beetles. These results confirm that the "brown-world" effect of predator beetles was due to cascading top-down control through coprophagous beetles to nutrient cycling and primary productivity. Our results also highlight potentially counterintuitive effects of climate warming. For example, global warming might significantly decrease animalmediated decomposition of organic matter and recycling of nutrients in a future warmed world.

Key words: alpine meadow; artificial warming; beetles; biodiversity and ecosystem function; QinghaiTibetan Plateau, China; coprophagy; dung decomposers; food webs; nutrient cycling; predator; top-down control; trophic cascade.
\end{abstract}

\section{INTRODUCTION}

Trophic cascades have long been recognized in the ecological literature (Hairston et al. 1960, Oksanen et al. 1981, Fretwell 1987, Stiling 1999), as predators indirectly affect plant community structure and ecosystem functioning via a top-down control on the abundance and diversity of herbivores (Schmitz et al. 2000, Borer et

Manuscript received 22 April 2010; revised 7 September 2010; accepted 16 September 2010. Corresponding Editor: A. M. Ellison.

${ }^{5}$ Corresponding author. Present address: Department of Biology, School of Life Sciences, Nanjing University, 22 Hankou Road, Nanjing 210093 China.

E-mail: shcs@nju.edu.cn al. 2005, Duffy et al. 2007, Bruno and Cardinale 2008). Top-down control by predators has proven to be strong in aquatic systems (Shurin et al. 2002), grasslands (Schmitz 2003), intertidal rocky shores (Paine 2002), and wetlands (Finke and Denno 2004, Duffy et al. 2005), all of which are systems involving food webs based on living plants. In contrast, the controlling role of predators in decomposer food webs is surprisingly unexplored. This probably reflects the fact that food web theories have traditionally focused on living organisms but have neglected detritus since the development of classical community ecology and ecosystem ecology in the 1950s (Moore et al. 2004). It may also be because predators are often assumed to have weak effects on decomposers, and perhaps assumed to be not important 
enough to alter ecosystem properties (e.g., Dyer and Letourneau 2003).

The lack of attention to detritus-based food webs is curious because detritus actually constitutes a large proportion of organic matter (particularly structural materials) and supports a great deal of biodiversity, which is important in the energy flow of ecosystems (Lindeman 1942, Odum 1969). Most terrestrial primary production is not consumed by herbivores (Cebrian 2004), and even of that part consumed by large herbivores, only very little is assimilated, e.g., in alpine pastures (Wu and Sun 2010). Thus, the decomposition rate of plant detritus (e.g., plant litter and excrement of large herbivores such as cattle) is critical to ecosystem nutrient cycling and primary production (Cebrian 2004, Nichols et al. 2008).

Interestingly, top-down control by predators in decomposer food webs, as we will explain, could have important and perhaps opposite effects on ecosystem process rates (e.g., detritus decomposition rate and plant growth rate) to those of the predators of living food webs. In plant-based food webs, where energy originates from living primary producers, predator control often cascades through herbivore density and diversity to facilitate plant growth (Schmitz et al. 2000, Shurin et al. 2002, Duffy et al. 2007), as suggested by the Green World Hypothesis (Hairston et al. 1960), which posited that in three-level food chains herbivores are more likely to be predator limited but seldom food limited. Later models like the Exploitative Ecosystem Hypothesis (Oksanen et al. 1981, Fretwell 1987, Oksanen and Oksanen 2000) generalized the idea of predator topdown control to food chains with more than or fewer than three trophic levels and argued that predators with an odd number of trophic levels increase the abundance of producers in food chains (e.g., the three trophic levels of Hairston et al. 1960).

Although little effort has focused on extending these concepts to detritus-based food webs, there is reason to believe that top-down control may have qualitatively different effects in "brown-world" webs. For example, in decomposer food webs, predators at odd trophic levels may negatively influence the abundance and effectiveness of detritus-consuming animals and hence reduce the detritus decomposition rate, damping ecosystem nutrient cycling and plant growth. Thus, the cascading influence of predators could both increase plant growth by reducing herbivory (green world) and simultaneously reduce plant growth by reducing nutrient recycling (brown world). Consequently, we hypothesize that enhanced effectiveness of predators should result in intensification of "brown-world effects" in detritus food webs. This idea has not been tested, because published studies on trophic cascades in detritus food webs have focused primarily on the resource-control effect, examining the top-down effect among organisms within particular decomposer taxa (e.g., bacteria, nematodes, and protozoa; see review by Wardle 2002, 2006), or have focused solely on direct consumers of detritus (e.g., Cebrian 2004, Srivastava et al. 2009).

Another issue is whether the cascading trophic effects of predators are ubiquitous and consistent between living and detritus food webs. As shown in several reviews (Schmitz et al. 2000, Shurin et al. 2002, 2006, Borer et al. 2005, Duffy et al. 2007), the strength of trophic cascades depends on herbivore species diversity, carnivore type (vertebrate vs. invertebrate), ecosystem type (terrestrial vs. aquatic systems), primary productivity, and predator metabolic factors. The top-down effect of predators is generally believed to be less frequent and weaker in detritus-based than in living food webs (Dyer and Letourneau 2003, Moore et al. 2004, Wardle et al. 2004, Wardle 2006), in part because of some particular properties of predator-detritivore interactions. For example, in a soil detritus food chain, microbes grew faster when they were grazed upon frequently by nematodes, indicating a compensatory growth in the microbes (Mikola and Setälä 1998). Therefore, microbial biomass might remain unchanged even though the number of nematodes was reduced by their predators, suggesting a limited trophic cascading effect. In contrast, another distinction between living and detritus food webs is that herbivores often induce antiherbivore defenses and compensatory growth of living plants that, in turn, reduce the impact of herbivores on plant populations (Schaller 2008), whereas detritus food webs are donor-controlled (Stiling 1999), with detritus quantity and quality being little affected by consumers. This difference may lead to a stronger cascading effect of predators in detritus-based webs than in food webs based on living plants (Srivastava et al. 2009). Accordingly, it is not clear whether the predicted "brown-world" role of predators is significant in detritus food webs.

The importance of predator control in brown world webs is likely to depend, as in green world webs, on diversity and species identity (and associated functional differences). The role of predator diversity in regulating plant and herbivore dynamics and ecosystem functioning is complex (Ives et al. 2005, Duffy et al. 2007, Bruno and Cardinale 2008, Letourneau et al. 2009). Many reports show that increasing predator diversity can either strengthen or weaken the predator effect on other trophic levels (e.g., Losey and Denno 1998, Sinclair et al. 2003, Byrnes et al. 2006, Schmitz 2009). As found in plant diversity-ecosystem functioning relationships, mechanisms underlying positive effects of predator diversity on predation rate could include sampling effects and complementary use of prey taxa or foraging microhabitats. In a diverse predator assemblage, species are more likely to utilize resources in different, complementary ways (e.g., exploiting prey at different times and in different ways that facilitate total prey capture; Letourneau et al. 2009) and the key predators are also more likely to be included (a sampling effect; Ives et al. 2005, Bruno and Cardinale 2008). Conversely, 
documented negative effects of predator diversity on top-down control are often attributed to intraguild predation, facultative hyperparasitism, or behavioral interference (Duffy et al. 2007, Rosenheim 2007, Bruno and Cardinale 2008, Letourneau et al. 2009). Such positive and negative effects are possible even when considering the impacts of two species rather than one (as in the present study). Additionally, top-down effects of predator diversity should be similar between living and detritus-based food webs, because the mechanisms (e.g., niche complementarity, facilitation, and sampling effects) underlying diversity effects can apply to consumers of either resource base. However, although these mechanisms have been demonstrated in studies of predator interactions, the ecosystem consequence of changes in predator diversity for decomposer food webs has scarcely been reported.

The influence of changing predator density or diversity is especially relevant because these factors may be more sensitive at high than low trophic levels under global change and strong anthropogenic pressures (Duffy 2002, Voigt et al. 2003). One such pervasive change is global warming resulting from increasing release of greenhouse gases and the changes in land and water use (Solomon et al. 2007). Mean global surface air temperature is predicted to increase by $1.4-5.8^{\circ} \mathrm{C}$ by 2100 relative to 1990 , according to the report of the Intergovernmental Panel on Climate Change (Houghton et al. 2001, Solomon et al. 2007). Corresponding with documented increases in temperature during the past 50 years, there have been significant shifts in spring phenology and distributions of many species (Peñuelas and Filella 2001, Root et al. 2003). Across different trophic levels, climate change may directly affect metabolic rates of both producers and consumers and also their life-history traits, thereby changing trophic interactions and ecosystem functioning (Preisser and Strong 2004, O'Connor et al. 2009, Barton and Schmitz 2009). For instance, in a warming experiment with marine plankton in microcosms, O'Connor et al. (2009) showed that warming increased primary production by autotrophs and basal metabolic rates of consumers and, as a result, the food web shifted toward increasing topdown control. In contrast, Barton and Schmitz (2009) showed that artificial warming transformed multipredator species effects and largely decreased the strength of predator control over plant biomass.

Because warming influences species distribution, phenology, and trophic interaction strengths, studies on the interactive effects of predator loss and global warming should help to predict how ecosystems may change under global climate change. Specifically, in detritus food webs, behavior and demography of both predators and detritivores may be dramatically changed by increased temperature, which could eventually change ecosystem process rates. Moreover, warming may directly influence plant growth, as demonstrated by a number of studies (e.g., Kudo and Suzuki 2003). It

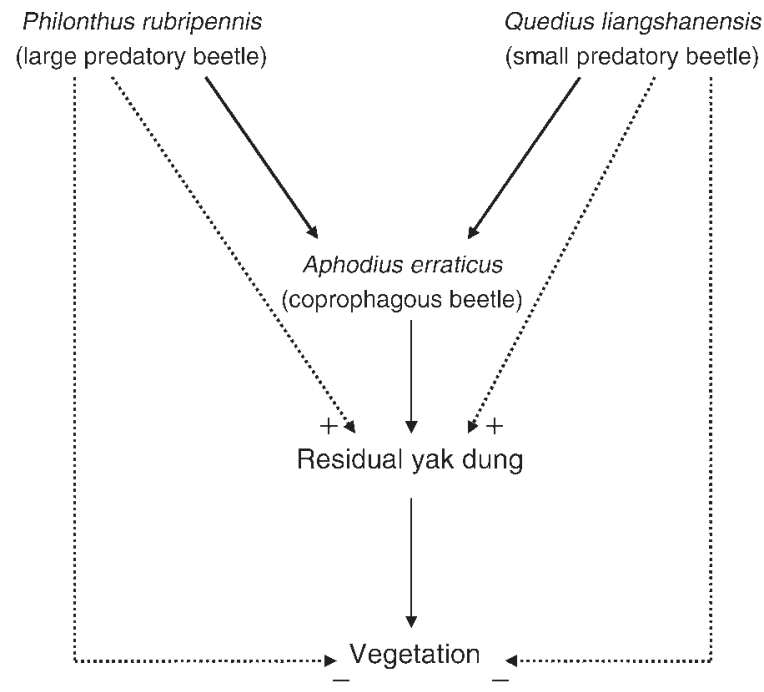

FIG. 1. Components of the decomposer food web used in the experiment. Solid and dotted arrows indicate direct and indirect interaction directions, respectively. The large and small predatory beetles can cause density reductions of the coprophagous beetle, which leads to an indirect positive effect (depicted by dotted arrows) on the loss rate of residual yak (Bos grunniens) dung and hence an indirect negative effect (depicted by dotted arrows) on the aboveground biomass of vegetation.

remains unclear how these combined processes will affect the functioning of detritus food webs. Several recent studies have explored effects of warming on living food webs (Preisser and Strong 2004, O'Connor et al. 2009, Barton and Schmitz 2009), but the empirical evidence in detritus food webs is lacking so far.

Alpine meadows, like high-latitude and cold regions generally, are especially sensitive to global warming (Walker et al. 2001). Many experiments conducted in these cold regions have demonstrated that increased temperature tends to directly enhance plant productivity (e.g., Kudo and Suzuki 2003). However, it remains unclear how climate-mediated changes in food web interactions may indirectly affect plant productivity. We conducted experiments to assess the combined effects of warming and predator loss in a Tibetan alpine meadow, one of the areas in the world most sensitive to global warming (Solomon et al. 2007). The study system consists of living plants, with cattle dung as detritus, which is consumed by coprophagous beetles that are preyed upon by predaceous beetles (Fig. 1). We manipulated the identity and number of predator species, employed artificial warming, and measured their effects on dung loss rate, soil nutrient content, and plant dry mass accumulation. Our ultimate goal was to examine whether and how predators of decomposers mediate ecosystem properties.

We document, for the first time to our knowledge, that predators of decomposers can indirectly reduce nutrient recycling and plant growth through a brownworld trophic cascade; moreover, the strength of this 
cascade is similar to that of aquatic living food webs dominated by large carnivores. We show that even a single predator species can produce a significant trophic cascade that leads to important changes in ecosystem function of this decomposer food web. Because a single predator species may influence both living and detritus food webs, this study raises an important question regarding how to define functional groups, even for a single species. Finally, this study also reveals that enhanced temperature and predator diversity interactively limit nutrient cycling and primary production through changing the dung food web.

\section{Methods}

\section{Study background and natural history}

This study was conducted in the Hongyuan Alpine Meadow Ecosystem Research Station of the Chinese Academy of Sciences $\left(32^{\circ} 48^{\prime} \mathrm{N}, 102^{\circ} 33^{\prime} \mathrm{E}\right)$, in the eastern part of the Qinghai-Tibetan Plateau. The study area was geologically formed by the plateau uplift of tectonic movement in the Cenozoic Period. The altitude is $3500 \mathrm{~m}$. The climate is of the continental cold type, characterized by short and cool spring, summer, and autumn and long winter. Annual mean temperature is $0.9^{\circ} \mathrm{C}$, with the maximum and minimum monthly means being $10.9^{\circ} \mathrm{C}$ and $-10.3^{\circ} \mathrm{C}$ in July and January, respectively. Annual mean precipitation is $690 \mathrm{~mm}$, fluctuating greatly between years, $80 \%$ of which occurs during May to August. The annual mean snow cover time is about 76 days.

The meadow where the study was conducted is mostly dominated by sedges such as Kobresia setchwanensis and K. pygmaea, and grasses such as Elymus dahuricus and Agrostis matsumurae. Forb species, including Saussurea nigrescens, Potentilla anserina, Aster alpine, Anemone trullifolia, and Thalictrum alpinum, are sometimes also abundant in the meadow. Total vegetation cover in midsummer is $>80 \%$, and average maximum plant height is $\sim 30 \mathrm{~cm}$. The growing season usually covers about three months from early June to late August or early September, depending on annual climate variations. The soil is characterized by high organic content $(215-280 \mathrm{~g} / \mathrm{kg})$ and low total nitrogen $(4.78 \mathrm{~g} \mathrm{~N} / \mathrm{kg})$ and phosphorus (1.02 g P/kg).

The pasture has been under intensive grazing for decades. Yaks (Bos grunniens) are one of the most important livestock species reared by local people. According to one of our field surveys during this study, the estimated population density is $\sim 10$ yaks/ha. The recorded yak dung density averages $\sim 3600$ pats/ha and sometimes can reach 5900 pats/ha, occupying $\sim 24 \%$ of the total grassland area in summer grazing pastures.

The decomposer community responsible for cattle (i.e., yak) dung removal is very complicated, as in other areas (e.g., Mohr 1943). Small invertebrates, bacteria, and fungi appear on the surface and inside of dung pats because the fresh cattle droppings give off odors (Mohr 1943, Lussenhop et al. 1980, Holter 1982). Although some studies (reviewed by Nichols et al. 2008) have suggested the importance of the microflora (bacteria and fungi) in regulating the activity and turnover of dung nutrients, macro-invertebrates such as beetles and flies are two major groups that contribute substantially to dung decomposition (Lussenhop et al. 1986, Wu and Sun 2010). In our study area, the two most abundant fly species are Scathophaga stercoraria and Calliphora vicina, and the coprophagous beetle species include Aphodius erraticus, A. rectus, A. rusicola, A. edgardi, Aphodius sp., Polydrusus sericeus, Canthon vigilans, Canthon sp., Germarostes aphodioides, Germarostes sp., Bitoma sp., Aphodius frater, Geotrupes egeriei, and Onthophagus schaefferi. Predaceous beetles include Philonthus rubripennis, Quedius (Microsaurus) liangshanensis, and Sphaerites sp. In the very late successional stage of dung decomposition, there may be spiders (Araneus marmoreus), centipedes (Scolopendra alternans), and beetle larvae emerging underneath the dung.

We focused in this study on the effects of changing composition of predaceous beetles on dung loss (i.e., decomposition) rates. We selected three beetle species for our experiment. One of them was the most abundant coprophagous species, Aphodius erraticus, and the other two were the most abundant predaceous beetles, Philonthus rubripennis and Quedius (Microsaurus) liangshanensis. The coprophagous species is an endocoprid that feeds and breeds within dung pats, according to the functional classification by Doube (1990). An independent pre-experimental survey showed that Aphodius erraticus (5.5-6.8 $\mathrm{mm}$ in adult body length) was active from April to October in dung pats, accounting for $>70 \%$ of the total number of coprophagous beetle inhabitants from June to September. Quedius liangshanensis is a small (2.9-3.5 mm in body length) but very abundant predaceous species, accounting for $\sim 70 \%$ of the total number of the carnivores, whereas Philonthus rubripennis is a large (14.6-15.8 $\mathrm{mm}$ in body length) and strong predaceous species, making up $\sim 15 \%$ of the carnivores in abundance. Individuals of the larger predator species were observed to directly prey on small or large individuals of Aphodius erraticus, whereas the smaller predator species often attacked the small prey or the large prey by group foraging. The ratio of Philonthus rubripennis, Quedius liangshanensis, and Aphodius erraticus in the field was about 1:4:10; the number of the coprophagous species was $\sim 40$ per fresh dung pat ( 1 day old). The relationships among the mentioned biological components are outlined in Fig. 1 for the study systems.

\section{Study design}

In the year before starting our experiment, we fenced a $100 \times 100 \mathrm{~m}$ plot, where the vegetation evenness of the species distribution was so high that $>90 \%$ of the higher plant species (harvested in this study) could be found in any $25 \times 25 \mathrm{~cm}$ patch (data not shown). We randomly installed 60 open-top chambers (OTC, $1 \times 1 \times 1 \mathrm{~m}$ ) in the plot, with at least $3 \mathrm{~m}$ distance between chambers. 
All of the chamber sides were surrounded with thin $(>0.1 \mathrm{~mm})$ steel screen of mesh size $0.2 \times 0.2 \mathrm{~mm}$, but half of the chambers were additionally covered with plastic screen with a sunshine transparency $>90 \%$. All of the chambers were sunk to the depth of $20 \mathrm{~cm}$ in soil. Temperature was measured in three chambers for each type using thermometers (model DS1921G, Maxim Integrated Products, Sunnyvale, California, USA). Over the course of the three-month experiment, the mean ambient temperature in the chambers without plastic screen (unwarmed chambers) was $12.1^{\circ} \mathrm{C}$ based on daily average (over $24 \mathrm{~h}$ of measurements made every 30 minutes). Mean temperature in the chambers with plastic screen (warmed chambers) was $2.3^{\circ} \mathrm{C}$ higher than that in the unwarmed chambers across all of the sampling days (Appendix A: Fig. A1a). The daily average relative humidity was mostly $>80 \%$; it was slightly higher in the ambient chambers $(89 \%)$ than in the warmed chambers (85.4\%) (Appendix A: Fig. A1b). In each chamber, $40 \%$ chlorpyrifos (O, O-diethyl O-(3, 5, 6-trichloro-2-pyridyl) phosphorothioate) was sprayed to kill the beetles more than one month before the beginning of the experiment. This chemical was demonstrated to have no apparent adverse effects on plant growth (Schmitz 2003).

We arranged the chambers for a three factor, twolevel factorial experiment involving temperature and presence/absence of large and small predators; hence there were eight treatments in total $(\mathrm{a} 2 \times 2 \times 2$ factorial of warming and presence/absence of both predator species). Each treatment consisted of six replicate chambers; 48 chambers were used in total. The predator manipulations were carried out with four treatments, i.e., large predators only (5 individuals of Philonthus rubripennis), small predators only (20 individuals of Quedius liangshanensis), both included (5 large and 20 small ones), and no predators included. Thus, the combined predator treatment used an additive design. In addition, one dung pat and 40 individuals of Aphodius erraticus were placed on the central part of each chamber.

Dung was collected in the early morning (before 7:00 A.M.) on 31 May 2009 from fresh droppings by yaks in a stall of a Tibet family, where chlorpyrifos was sprayed at night before collection. The dung was thoroughly mixed in a big bucket, and then was divided into individual pats using a circular metallic mold. The pats were $20.5 \pm 0.5 \mathrm{~cm}$ in diameter and $1080 \pm 87 \mathrm{~g}$ in fresh mass ( $\sim 5 \mathrm{~cm}$ thick); all measurements are mean $\pm \mathrm{SE}$. Beetles were collected with 10 dung-baited traps around the fenced plot for two days (30-31 May 2009), until enough individuals were captured to conduct the experiment. We selected only the medium-sized beetles for each species for the experiment.

The experiment began on 1 June and ended on 31 August 2009. At the end of the experiment, the remaining dung was collected and the aboveground plant parts surrounding the original dung pats were harvested. The harvested area was $942.5 \mathrm{~cm}^{2}$, occupying a circular belt of $10 \mathrm{~cm}$ (from the edge of the dung pats to $10 \mathrm{~cm}$ away from the edge). The dung and plants were weighed separately after being dried at $75^{\circ} \mathrm{C}$ for $48 \mathrm{~h}$. Three soil cores ( $5 \mathrm{~cm}$ in diameter and depth) beneath the harvested plants around each dung pat were also sampled on the same day when the dung pats were collected. Each soil sample was mixed well and sieved to exclude plant roots and beetles that came from the dung pats. Then, total soil $\mathrm{N}$ concentrations were determined by the Kjeldahl method and $\mathrm{P}$ concentrations were determined using spectrophotometric colorimetry (Unicam-200; Unicam, Cambridge, UK).

In parallel with the experiment just described (hereafter called the "major experiment"), we conducted a second ("accessory") experiment to explore the mechanisms underlying the predator effect and the warming effect on the dung loss. Because dung pats were sampled only once in the major experiment, it is impossible to deduce the relationships among predators, prey (the coprophagous beetles), the dung loss rate, and the warming effect on beetle population dynamics, which are critical to test whether the predators had a significant control over the abundance of the prey beetles and, hence, on the dung loss rates. The purpose of the accessory experiment was to clarify the time courses of beetle abundance and dung loss rate, so that the response patterns of the major experiment could be better understood and explained. The design of the accessory experiment was similar to that of the major experiment, but the scale was smaller. Each dung pat was $\sim 400 \mathrm{~g}$ in fresh mass, and was placed into a squareshaped bag $(20 \times 20 \mathrm{~cm})$ made of nylon cloth $(0.2 \times 0.2$ mm mesh size) on 31 May 2009. Then, the same four predator treatments just described were imposed, but on a smaller scale: large predators only (3 individuals of Philonthus rubripennis); small predators only (15 individuals of Quedius liangshanensis); both predators included (3 large and 15 small individuals); and no predators included. In each bag, 20 coprophagous beetles were added.

The total number of dung bags was 216, and they were divided among six warmed and six unwarmed chambers of each treatment. Not all chambers shared the same number of dung bags, but they were approximately evenly distributed within each chamber. During the course of this experiment, we sampled the dung bags nine times, with three replicates for each treatment. The sampling times were on 4 June (after 3 days), 7 June (after 6 days), 11 June (after 10 days), 16 June (after 15 days), 21 June (after 20 days), 26 June (after 25 days), 7 July (after 35 days), 21 July (after 50 days), and 21 August (after 80 days). As in the previously described experiment, the remaining dung was weighed and living beetles (including both larvae and adults) were collected and counted, but we did not sample plants. 

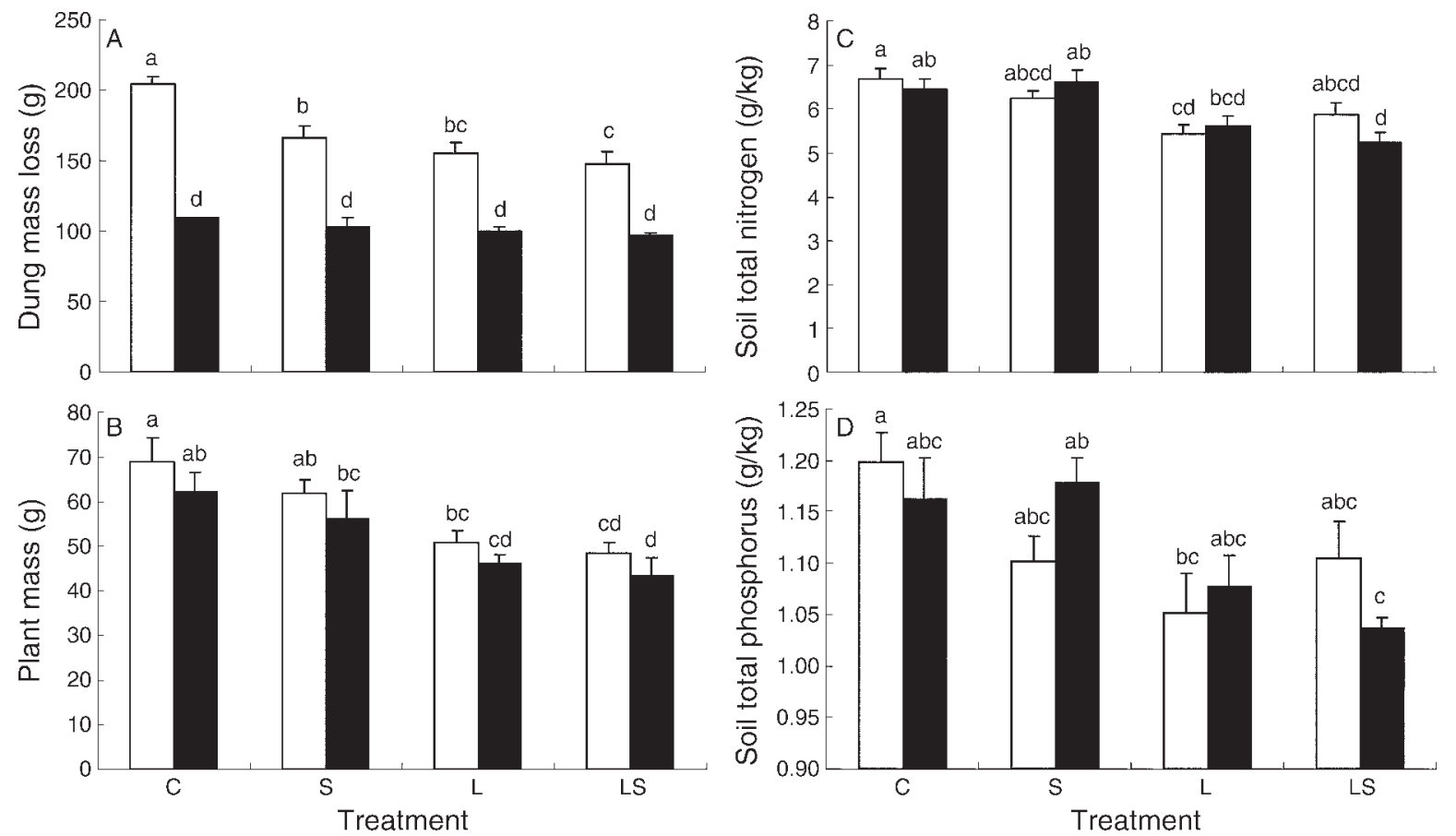

FIG. 2. (A) Dung loss, (B) plant biomass accumulation, (C) soil total nitrogen concentration, and (D) soil total phosphorus concentration of the circular belts surrounding yak dung pats in different treatments of the major experiment in a Tibetan alpine grassland. In the three-factor, two-level factorial experiment involving temperature and presence/absence of large and small predators, there were eight treatments in total. The open and solid columns represent the unwarmed and warmed treatments, respectively. Predator treatments are: C, control, with no predators; S, small predator only; L, large predator only; and LS, both large and small predators included. For details, see Results: Role of predator interaction and warming on ecosystem function. Values are means + SE. Different lowercase letters above the bars indicate significant differences at $P<0.05$.

\section{Data Analysis}

All of the data were tested for normality prior to analyses. Three-way ANOVA was employed to determine the effects of temperature, predator identity (including two factors of predator type and presence/ absence), and their interactions on harvested plant mass that accumulated during the experiment (primary productivity) and dung loss (i.e., decomposition, the dry mass loss during the experiment). Similarly, for the second, accessory experiment, three-way ANOVA was used to examine the effects of the treatments on dung loss (the dry mass loss between two sampling times) and the number of living coprophagous beetles. In both experiments, once a significant effect was detected, the difference between the treatments was determined using post hoc Tukey tests.

Linear regression analyses were conducted to determine the relationship between dung loss rate and plant biomass accumulation in the major experiment and between the number of living predatory and coprophagous beetles and the dung loss rate in the accessory experiment. Moreover, based on the mean dung loss rate or plant mass gain in treatments with large or small predators only, we predicted the rates expected with both predator species by averaging the two means. Then, we assessed the difference between the prediction and observation with a $t$ test. Finally, we estimated the strength of the top-down effect of predators on loss rate and primary productivity as the $\log$ ratio $[\ln (\mathrm{Np}+/ \mathrm{Np}-)]$ of dung dry mass loss and dry plant mass accumulation in the chambers in the presence $(\mathrm{Np}+)$ and absence $(\mathrm{Np}-)$ of specific predators (Schmitz 2003).

\section{Results}

\section{Role of predator interaction and warming on ecosystem function}

All three factors (presence of large and small predators and warming) significantly affected the dung loss rate, as did the interactions between predators and temperature (Fig. 2, Table 1: ANOVA, all $P<0.05$ ). Both the large and small predatory beetles significantly decreased dung loss rates in the unwarmed but not the warmed chambers, and the large predator tended to have a slightly greater effect than that of the small one. In the unwarmed plots, the presence of both predator species slightly strengthened the inhibiting effect on dung loss over that of single predator species, although this effect was not significant for the large predator. The interactive effect of the two predator species on dung loss rate was marginally significant (Table $1: F=3.832$, $\mathrm{df}=1,40, P=0.057)$. Warming markedly decreased dung loss rates (Fig. 2A), regardless of whether or which 
TABLE 1. Results of three-way ANOVAs showing the effect of temperature (T), presence of small (S) and large (L) predators, and their interactions on dung loss, primary productivity, and nutrient concentrations in the major experiment in a Tibetan alpine grassland.

\begin{tabular}{|c|c|c|c|c|c|c|c|c|}
\hline \multirow[b]{2}{*}{ Source } & \multicolumn{2}{|c|}{ Dung loss } & \multicolumn{2}{|c|}{ Plant productivity } & \multicolumn{2}{|c|}{ Total nitrogen } & \multicolumn{2}{|c|}{ Total phosphorus } \\
\hline & $F$ & $P$ & $F$ & $P$ & $F$ & $P$ & $F$ & $P$ \\
\hline $\mathrm{T}$ & 228.716 & $<0.001$ & 3.866 & 0.056 & 0.271 & 0.606 & 0.00 & 1.000 \\
\hline $\mathrm{L}$ & 22.916 & $<0.001$ & 28.555 & $<0.001$ & 33.842 & $<0.001$ & 18.16 & $<0.001$ \\
\hline $\mathrm{S}$ & 10.420 & 0.002 & 2.476 & 0.123 & 0.054 & 0.817 & 0.63 & 0.431 \\
\hline $\mathrm{T} \times \mathrm{L}$ & 8.902 & 0.004 & 0.060 & 0.807 & 0.817 & 0.371 & 0.89 & 0.352 \\
\hline $\mathrm{T} \times \mathrm{S}$ & 4.369 & 0.042 & 0.010 & 0.919 & 0.121 & 0.729 & 0.04 & 0.839 \\
\hline $\mathrm{L} \times \mathrm{S}$ & 3.832 & 0.057 & 0.506 & 0.481 & 0.255 & 0.616 & 1.19 & 0.282 \\
\hline $\mathrm{T} \times \mathrm{L} \times \mathrm{S}$ & 2.576 & 0.116 & 0.013 & 0.909 & 4.781 & 0.035 & 5.57 & 0.023 \\
\hline Error & 9104.6 & 227.6 & 3857.4 & 96.4 & 13.1 & 0.3 & 0.2 & 0.0 \\
\hline
\end{tabular}

Notes: The large predatory beetle (L) is Philonthus rubripennis; the small predatory beetle (S) is Quedius liangshanensis. For all tests, $\mathrm{df}=1,40$.

predators were included, such that the predator effect on the dung loss was erased in the warmed chambers.

Three-way ANOVAs revealed that dry-matter yield of the plants harvested in the circular belts around the dung pats was significantly reduced by the large predator (Table 1: $F=28.555$, df $=1,40, P<0.001$ ), reduced more modestly by temperature (Table $1: F=$ $3.866, \mathrm{df}=1,40, P=0.056$ ), and unaffected (reduced but not significantly) by the small predator (Fig. 2B). Warming consistently, but not significantly, decreased the plant productivity in each pair of treatments. Presence of the two predators together decreased dung loss more than both the control and the treatment with only the small predators included. However, the interaction between the large and small predators was not significant and the two predators additively decreased the plant biomass in both warmed and unwarmed chambers.

The total soil $\mathrm{N}$ and $\mathrm{P}$ concentrations at the end of the experiment were higher than the background values before the experiment started. Neither temperature nor the small predators significantly affected soil nutrient status (Table 1; all $P>0.05$ ), but the large predator, together with the interaction among temperature and large and small predators, significantly influenced both the $\mathrm{N}$ and $\mathrm{P}$ concentrations (Table 1 ; all $P<0.05$ ). Large predators reduced both $\mathrm{N}$ concentration (Fig. 2C) and $\mathrm{P}$ concentration (Fig. 2D) relative to controls, whether the chambers were warmed or unwarmed. Control treatments had the highest concentrations of both nutrients, whereas warmed treatments with both large and small predators had lowest.

The effect strengths $[\ln (\mathrm{Np}+/ \mathrm{Np}-)]$ of the large predator Philonthus rubripennis on dung loss and plant dry mass accumulation (productivity) were estimated to be -0.28 and -0.31 , respectively, whereas those of the small predator Quedius liangshanensis were -0.21 and -0.11 , respectively, in unwarmed chambers. In the warmed chambers, effect strengths of the large predator on dung loss and plant productivity were -0.09 and -0.30 , respectively, and effect strengths of the small predaceous beetle were -0.06 and -0.09 , respectively.
Thus, warming strongly reduced the effects of both predators on dung loss.

Dung loss rates were significantly and positively correlated with plant biomass and soil $\mathrm{N}$ and $\mathrm{P}$ concentrations in the unwarmed chambers, but not in the warmed chambers (Fig. 3). However, soil phosphorus concentrations were significantly and positively associated with plant biomass in both types of chambers (Fig. 3).

\section{Accessory experiment: relationships among predatory \\ beetles, coprophagous beetles, and dung loss rate}

Consistent with the findings in the major experiment, the results of ANOVA of the accessory experiment showed that predators and temperature generally and significantly decreased dung loss during the course of the experiment. However, the effect of any specified factor varied across sampling times (Appendix B: Table B1). For example, temperature had no significant effect on dung loss on the second, third, or seventh sampling days (Appendix B: Table B1). The large predatory beetle alone, as well as the two predators together, had a significant effect throughout the experimental period ( $P$ $<0.001$ ), but the effect of the small predator alone was not significant on most sampling days except for the 25th day and the last sampling time (Appendix B: Table B1). The combination of the two predators also had an antagonistic effect on dung loss at most sampling times (Appendix B: Table B1; $P<0.001$ ). For example, at the end of the experiment the dung loss rate was greater in the treatments with the smaller predators than with the large ones, but the loss rate of the treatments with both predators was in between (Appendix C), indicating a nonadditive (negative) interaction between the large and small predators.

Both temperature and predators also had strong effects on the number of living coprophagous beetle adults (Fig. 4A-D). The response of prey beetle abundance to predators was generally similar to that of the dung loss (Appendix B: Table B1), but the prey larval abundance was minor and unaffected (Appendix B: Table B1). In particular, the large predator strongly 


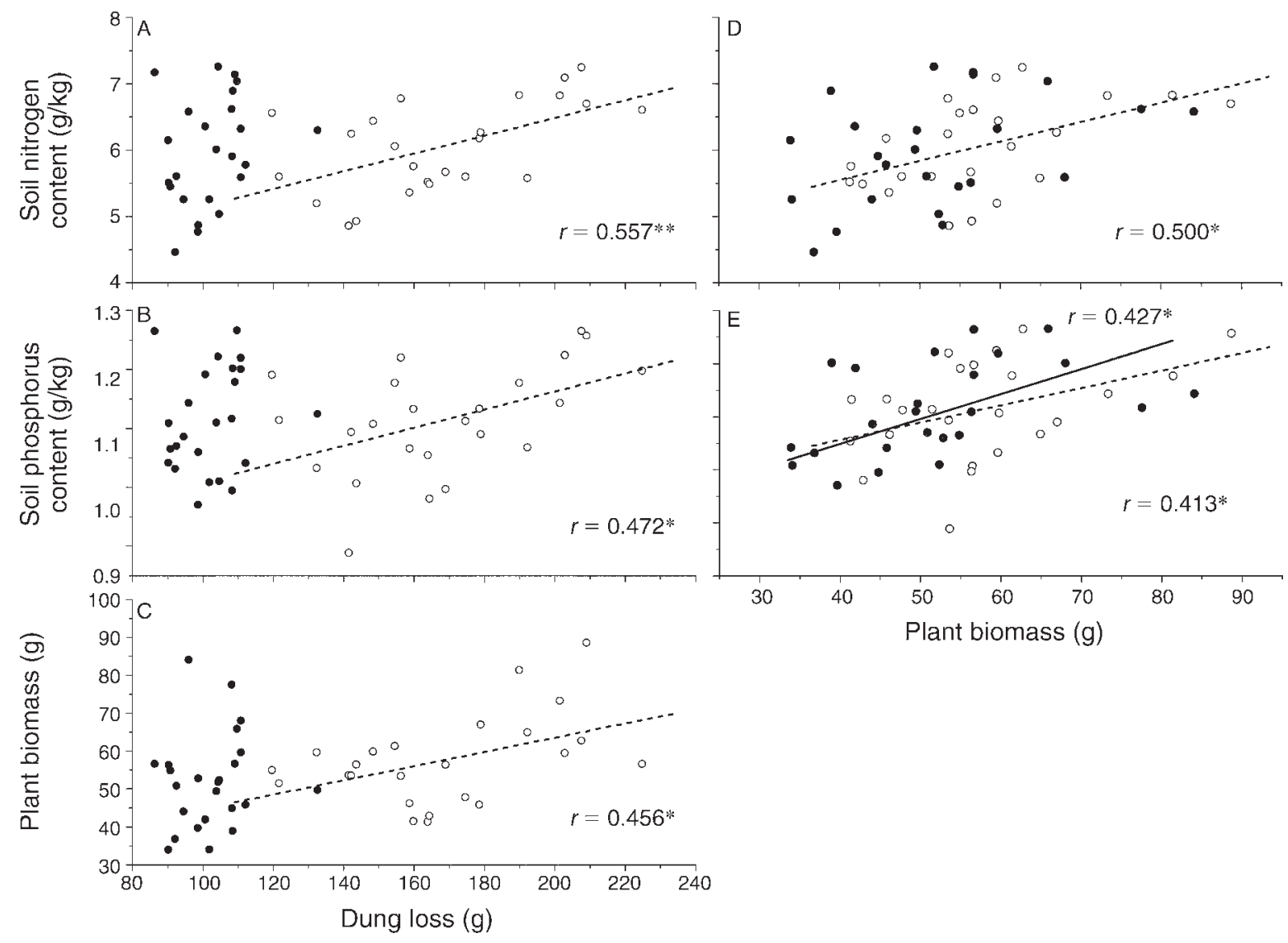

FIG. 3. Relationships among dung loss, soil nutrient concentrations, and plant biomass in the warmed (solid circles and solid line) and unwarmed (open circles and dashed line) chambers of the major experiment. (A) Dung loss and soil N concentration, (B) dung loss and soil $\mathrm{P}$ concentration, (C) dung loss and plant biomass, (D) soil $\mathrm{N}$ concentration and plant biomass, and (E) soil P concentration and plant biomass. Regression coefficients $(r)$ and significance levels are provided for each significant relationship.

$* P<0.05 ; * * P<0.01$.

decreased the abundance of prey beetles on all sampling dates. However, the effect of the small predator and temperature were inconsistent during the course of the experiment (Appendix B: Table B1).

The dung loss rate at each sampling time was significantly and positively correlated with the number of coprophagous beetles within the dung pats across both warmed and unwarmed chambers (Fig. $5 ; r^{2}$ ranging between 0.4 and 0.8; Appendix B: Table B2). The number of large predators was negatively correlated with both the dung loss and the abundance of the prey beetles at almost every sampling time $\left(r^{2}\right.$ ranging between 0.4 and 0.8; Appendix B: Table B2). However, the number of small predators did not have a consistently significant association with either the dung loss or the abundance of the living prey beetles.

\section{DisCUSSION}

\section{Role of predators in ecosystem functioning}

Predation is one of the primary determinants of ecosystem structure and functioning (Sih et al. 1998, Shurin et al. 2002, Halpern et al. 2006, Duffy et al.
2007), and the top-down cascading effects of top predators have been substantially studied in living food webs in recent decades. In contrast, the potential cascading role of predators in detritus-based food webs is poorly studied. We have demonstrated here that predators can produce a significant trophic cascading effect through the decomposer community, which reduced the abundance of living prey (coprophagous beetle species) and, in turn, the decomposition rate of cattle dung, soil nutrient concentrations, and plant production in the alpine meadow. This suggests a farreaching role of predators in regulating ecological processes in this system.

Although our study involved only one growing season, the magnitude of plant productivity surrounding the dung, the beetle density, and the ratio of predator to coprophagous beetle density are generally consistent with those typically observed in the ecosystem of the study site (see Methods: Study background and natural history). Although many small invertebrate species can colonize and appear on the surface of and inside dung pats, subsequently leading to rapid biotic succession 


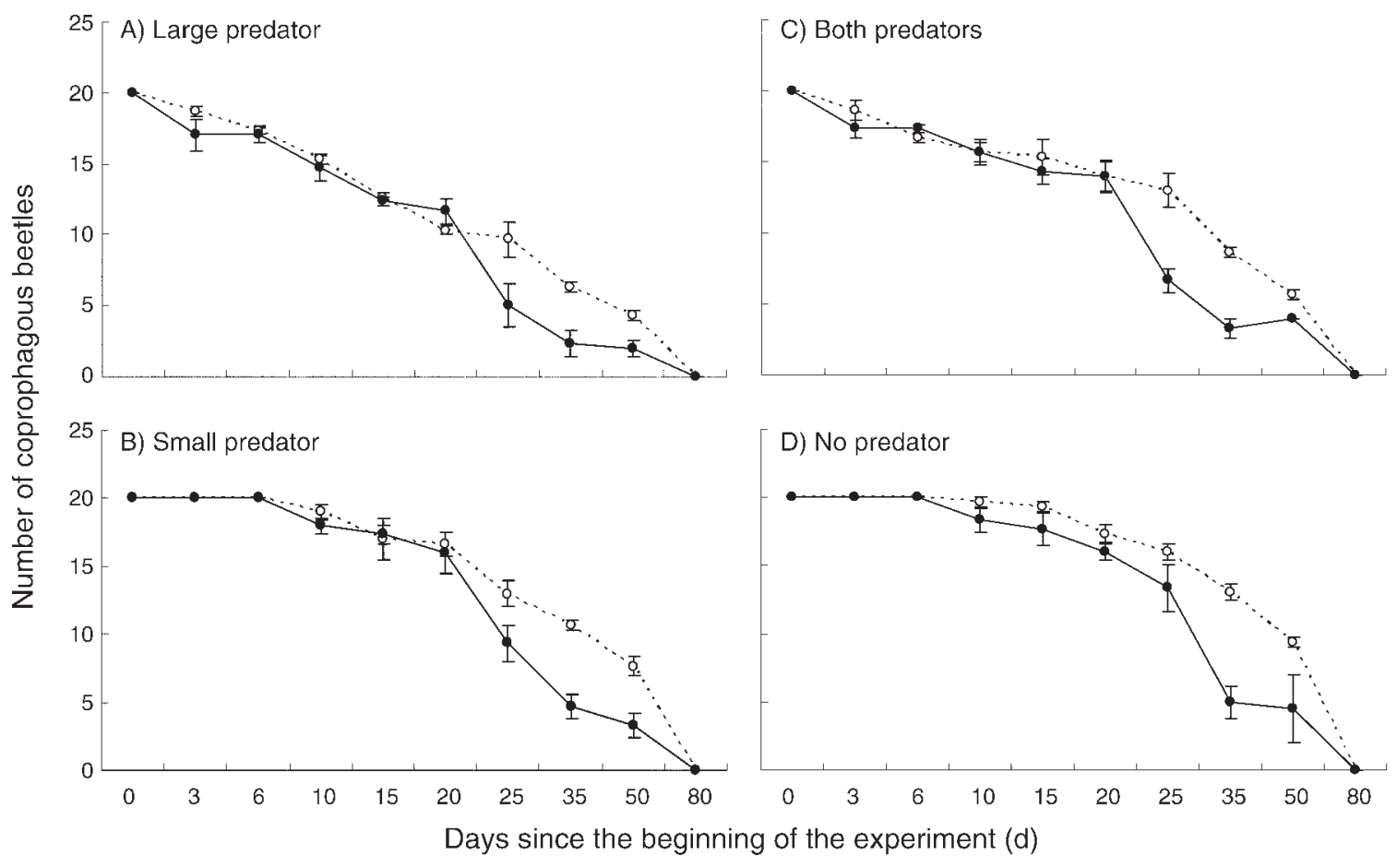

FIG. 4. Abundance (mean \pm SE) of coprophagous beetles (Aphodius erraticus) in unwarmed chambers (dashed line) and warmed chambers (solid line) for four different treatments during the course of the accessory experiment in an alpine grassland. The four treatments are represented by inclusion of (A) the large predator species only, (B) the small predator species only, (C) both predators, and (D) no predators (control).

(Mohr 1943, Lussenhop et al. 1980, Holter 1982), we only manipulated the diversity and abundances of beetles at the start of the experiment. The nature of the experiment thus permits us to evaluate our results in comparison with other study systems.

The cascading effects of predators on nutrient cycling and plants in our experiment was as strong as, or even stronger (e.g., the $\ln (\mathrm{Np}+/ \mathrm{Np}-$ ) values for the large predator) than those found in many explored food webs based on living plants (see case studies in Schmitz et al. [2000: Table 1] and in the terrestrial and marine plankton systems of Shurin et al. [2002: Fig. 1]). Previous studies reporting strong predator control over ecosystem function are often either from aquatic ecosystems, in which plant tissue is more nutritious and more easily decomposed than in terrestrial ecosystems, or from systems with large vertebrate carnivores (Oksanen and Oksanen 2000, Schmitz et al. 2000, Shurin et al. 2002, Borer et al. 2005, Halpern et al. 2006, Schmitz 2009), which may strictly control the density and behavior of large herbivores that effectively decrease plant production. The top-down effect of manipulation of small predators on ecosystem properties usually requires a long time (e.g., three years; Schmitz 2003, 2008) to take place if simulated closely to nature. Furthermore, previous studies on detritus-based food webs have suggested that the direction and magnitude of the predator effect on lower trophic levels is variable (positive, negative, or neutral) and mostly minor in both soil and foliar detritus food webs (De Ruiter et al. 1995, Wardle et al. 2004, Wardle 2006). In fact, few studies have tested the effects of predators on ecosystem functioning in detritus-based food webs (Krumins et al. 2006, Wardle 2006). Thus, the present study is novel in indicating that significant trophiccascading effects can occur in terrestrial, detritus-based food webs.

We demonstrated a cascading "brown-world effect" by the predators of the decomposer food webs, i.e., predators indirectly reduced plant growth by inhibiting nutrient recycling by decomposers. This "brown-world effect" of decomposer predators, if applicable to soil food webs, may partly explain why the soil is a brown world, i.e., why organisms do not break down all the carbon in the soil, although the brown world previously has been attributed to (1) the chemical properties of detrital carbon that make it more difficult to consume than living plants, and (2) the fact that most decomposers are small relative to many of the herbivores eating green plants (Allison 2006). The "brown-world effect" demonstrated in our study is in contrast to the situation in living ("green world") food webs, in which predators indirectly increase plant growth by reducing herbivory. Although the predators in both types of food webs can control the diversity and abundance of animals at the herbivore trophic level, they influence primary 

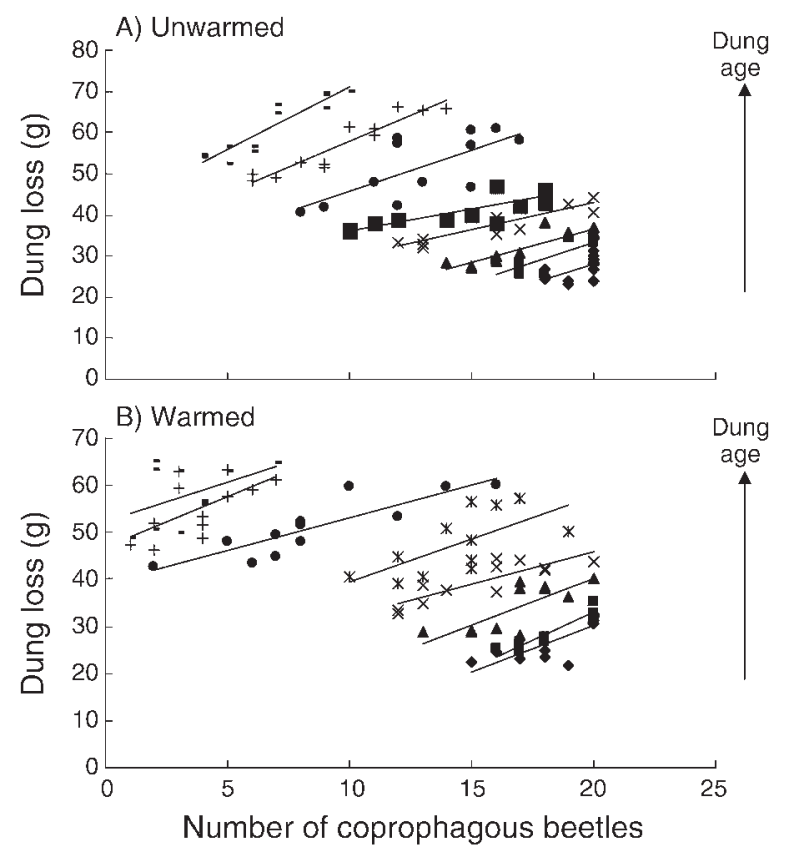

FIG. 5. Relationships between dung mass loss and the abundance of coprophagous beetles (Aphodius erraticus) in the (A) unwarmed and (B) warmed chambers of the accessory experiment. Different symbols represent different sampling dates. Upward arrows to the right denote increasing dung age (days since the beginning of the experiment); all regression lines are significant $(P<0.05)$. For details, see Results: Accessory experiment: Relationships among predatory beetles, coprophagous beetles, and dung loss rate.

productivity and probably nutrient cycling rates in opposite ways. This contrasting role raises an important question for the development of food web theory and for prediction and modeling of ecosystem function. Specifically, a single species can be a predator in both living and detritus-based food webs. For example, the predaceous beetles in our system feed both on coprophagous beetles located in the (brown) food webs inside dung pats, and on larvae of flies that may partly be associated with a (green) living food web. This phenomenon increases the ecosystem complexity, and is potentially analogous to the role of large, mobile vertebrates in linking food webs of spatially separated habitats, which may have important consequences for the stability of those systems (McCann et al. 2005). The dual role of a single predator species in our system is also similar to the well-recognized fact that a single species can stand at different trophic levels of living food webs. Moreover, this contrasting role of given predators in the two types of food webs further suggests that even a single species can play contrasting roles in ecosystem functioning, and should be included within two different functional groups; this idea has not been adequately explored nor thoroughly expressed in current explorations of species functional types.
The observed strong top-down control by predators in our study system could be a consequence of one or both of two factors, together with the presumed negative effect of predators on prey abundance (Appendix B: Table B1). One is that coprophagous beetles are the most important dung decomposers in the study site. Although both flies and coprophagous beetles are usually two major species contributing to dung decomposition in the study site, the role of flies is modest when the coprophagous beetles are included, because flies often spend a shorter time within dung pats than do beetles (Mohr 1943) and are often outcompeted by beetles (Ridsdill-Smith et al. 1986, Wu and Sun 2010). This has been widely suggested by a strong negative relationship between the two groups in both laboratory and field experiments (Bornemissza 1970, Feehan et al. 1985, Ridsdill-Smith et al. 1986, Bishop et al. 2005). In a previous independent study, we also showed that coprophagous beetles could remove dung as quickly as both beetles and flies did together (Wu and Sun 2010). In the present study, we sometimes observed flies visiting the dung pats, but the predaceous beetles might have fed on fly eggs and larvae, thereby limiting the role of flies in decomposition.

The second factor potentially contributing to the strong top-down control that we observed is that the alpine grassland is largely nutrient limited for plant growth. The limitation is evident from our investigation. For example, the highest nutrient contents were associated with the highest plant biomass, and vice versa for the lowest ones (Fig. 2B-D), and in both warmed and unwarmed chambers, plant biomass was positively correlated with soil nutrient contents. As noted, the total soil organic matter content is high, but the nutrient availability is relatively low at this study site compared to other grasslands (e.g., Yamada et al. 2007). This is often attributed to low temperature that slows the decomposition rate of organic matter and the rate of nutrient release into plant rhizosphere zones. Either or both of these two factors might have permitted predators to have a substantial indirect influence on primary productivity in this study. Additionally, the dung was not contaminated with antibiotics in our system, so the dung lacked defenses against beetles. Thus, the mechanism underlying the top-down effect of the predators on ecosystem function in our system is similar to the phenomenon of "the top-down is bottomup" described in Moore et al. (2003), who found that predators in the rhizosphere regulate aboveground community dynamics. In our systems, predators influenced the dung loss rate and soil nutrients status in a traditional "top-down" manner, but plant growth and biomass accumulation, in turn, were affected by a "bottom-up" effect of soil nutrients. This is different from the top-down control of predators in living food webs, where nutrient cycling is rarely taken into account. The detailed mechanisms underlying such "top-down" 
and "bottom-up" effects should include consideration of the predator-prey dynamics.

\section{Predator identity, traits, and diversity effects on coprophagous beetles}

Biodiversity-ecosystem functioning (BEF) relationships have been extensively examined, beginning with pioneering research in plant assemblages (reviewed by Tilman 1999, Hooper et al. 2005). Consumer and predator traits and diversity can similarly be important to ecosystem functioning, although these effects (that include habitat domain and hunting mode) become more complex as one considers multitrophic interactions (Sih et al. 1998, Duffy 2002, Ives et al. 2005, Duffy et al. 2007, Bruno and Cardinale 2008, Wilmers et al. 2007, Schmitz 2008, Barton and Schmitz 2009). As is true of $\mathrm{BEF}$ research generally, this research has focused mostly on living food webs (but see Srivastava et al. 2009). Consistent with this prior research in green food webs, we revealed similar mechanisms for the predator diversity effect on prey abundance in our detritus food web.

Predator identity strongly influenced the ecosystem properties, as effects of the large predator were consistently, although sometimes only slightly, greater than those of the small predator on both dung loss and primary productivity (Fig. 2A, B). Although the individual size of large predators was several times of that of small predators, the total mass was generally comparable between the two predator species. The difference in metabolic rates between the predators is unlikely to explain the difference in strength of the top-down effect, because the small predator should have consumed more at a given total body mass according to the ecological metabolic theory (e.g., Kleiber 1932, Brown et al. 2004). We tend to attribute the difference in strength of topdown control between the large and small predators to the difference in hunting ability and behavior between them.

Specifically, we observed that the large predator mostly hunted directly and actively on the coprophagous beetles even though their body sizes were comparable. The prey beetles often avoided the large predator by entering the wet part of dung pats where the large predators usually did not visit. Small predators were rarely found to directly attack the coprophagous beetles, but their disturbance and sometimes predation risk might have decreased the efficiency of the prey foraging. Consistently, the number of large predators was generally stable, whereas the number of small predators declined substantially from the beginning of the experiment (Appendix D: Fig. D1a, b), possibly because of the low hunting efficiency of the small predators. As a result, the number of coprophagous beetle adults declined quickly in the treatment with the large predators, but remained relatively large and stable in the treatment with only small predators included (Fig. 4A-D). Adults of coprophagous beetles have mouth- parts that allow them to feed only on dung liquids and smaller dung particles, and meanwhile filter out large and indigestible plant fragments (Holter and Scholtz 2007). Because the abundance of coprophagous beetle larvae was very small and did not differ significantly among treatments (Appendix B: Table B1; Appendix E: Fig. E1), the difference in dung loss could be accounted for primarily by variation in the abundance of adult beetles. In general, according to Trussell and Nicklin (2002), both the large and small predators might have strong, behaviorally mediated indirect effects on the coprophagous beetles, but the large predators might also have a strong density-mediated effect on the prey by direct consumption.

With the factorial experimental design, we also detected that the interaction between the large and small predators dampened their collective influence on ecosystem functioning through dung decomposition. Considering that the interaction effect on dung loss was marginally insignificant $(P=0.056)$ in the major experiment, but consistently significant during the course of the accessory experiment (except for the 15th day), we speculate that the two predators have a nearly antagonistic effect on herbivore suppression because their combined impact on dung loss was less than the sum of their individual impacts (e.g., the last sampling of the accessory experiment; Appendix C). This interaction is inconsistent with a recent meta-analysis by Srivastava et al. (2009), who reported a strong top-down effect of consumer diversity on enhancing decomposition rate in brown food webs. Our finding is also in contrast to many previous studies that revealed synergistic effects for insect predators (e.g., Soluk and Collins 1988, Losey and Denno 1998, Letourneau et al. 2009). A potential mechanism could be due to asymmetrical competition for prey beetles between the two predator species. As noted, the large predators are almost five times larger than the small ones and thus might have an overwhelming advantage in capturing prey; the top-down effect of the small predators on prey would be damped because of the limited number of prey. Furthermore, we observed that some corpses of the small predators had apparent traces of being attacked by the large predator species. This suggests intraguild predation, although we cannot exclude the possibility that the attack happened after the death of the small predators due to starvation. These findings are consistent with those of previous studies arguing that antagonistic interactions between predator species are more likely to happen when interspecific interference and/or intraguild predation are involved (Oksanen et al. 1981, Rosenheim et al. 1999, Finke and Denno 2004, Barton and Schmitz 2009).

Nevertheless, we also occasionally noticed, when we sampled beetles from treatments with both species, that most small predators were located in the central part of the dung pats, whereas the large ones lived in the edge part of the pats, although we did not systematically follow the behavioral changes of the coprophagous 
beetles in the treatment with both predators. This suggests that the two predator species differed in microhabitats, avoiding strong competition but allowing for possible complementarities. Such a distribution pattern should help to increase the predation efficiency through predator facilitation (Soluk and Collins 1988, Losey and Denno 1998, Sih et al. 1998), particularly for the small predators, and meanwhile should decrease the foraging efficiency of the coprophagous beetles, as the large predator drives the prey beetles to the center of the pat where they become vulnerable to the small predator. Thus, this difference in microhabitat might have confounded the strength of antagonistic interaction between the predator species, so that the combined effect of the predator-predator interaction was not highly antagonistic but close to additive (e.g., in the major experiment). To our knowledge, our experiment is the first to systematically demonstrate that the interaction of predators on decomposers can affect ecosystem function in a brown-world system.

\section{The warming effect on predator-ecosystem functioning relationship}

It is always a challenge to predict and quantify the effect of global change on species interaction (Sanford 1999, Tylianakis et al. 2008). Many efforts have attempted to reduce the uncertainty about how mechanisms of direct and indirect species interactions will change not only from mathematical models (e.g., Emmerson et al. 2004, 2005) but also from experimental analyses (Barton and Schmitz 2009, Tylianakis et al. 2008). Recent studies have also shown that global warming may significantly change the strength of the indirect effect of top predators on their prey's resource in living food webs, and hence fundamentally alter system functioning (Wilmers and Getz 2005, Wilmers and Post 2006, Wilmers et al. 2007, Tylianakis et al. 2008). Similarly, in this study, we found that warming altered the effect of predators on ecosystem functioning in the detritus food web, but the effects on nutrient cycling and primary productivity were different, presumably because the mechanism involved responses of multiple trophic levels (soil nutrients, plants, predators, and perhaps also coprophagous beetles) to temperature change, in a much more complicated interaction than those in living food webs.

The top-down effect of predator diversity was strongly affected by temperature. In particular, all of the biological effects resulting from action of the two predator species on dung loss rates disappeared in the warmed chambers. Such a finding is similar to the results of Kishi et al. (2005), who found that water temperature determined the strength of top-down control in a stream food web, and of Sanford (1999) who found that a very small temperature change could dramatically regulate the impacts of a keystone predator, Pisaster ochraceus, on its principal prey in rocky intertidal communities. In a marine experimental food web, O'Connor et al. (2009) recently also showed that a small temperature increase may significantly shift food web structure and productivity in a predictable way (e.g., shifting toward consumer control when resources were enriched). It seems hard to predict whether warming will lead to a consumer or resource control in detritus food webs, because the feedback between resources and consumers is usually less frequent in detritus than in living food webs (Stiling 1999). However, the temperature effect did account for a large part of the variance in both the dung loss rate and plant growth in our study (Table 1).

Experimental warming decreased the dung loss to a surprisingly low level, eliminating all of the differences among predator manipulation treatments (Fig. 2A). This is similar to the result of Barton and Schmitz (2009), who suggested that predator functional diversity may become diminished as a consequence of climatealtered predator-predator interactions. In our study, this effect is presumably due to higher temperature enhancing evaporation and thus reducing dung water content, which indirectly influenced dung loss rates. We did not measure the water content for the whole course of the first experiment, but at the end of the first experiment, the dung water content was significantly lower in the warmed than in the unwarmed chambers for all of the predator treatments. Although dung water content varied considerably during the course of the second experiment (Appendix E: Fig. E2), partly because of the rainfall events (Appendix A: Fig. A1b), it was generally and significantly smaller in the warmed than in the unwarmed chambers (Appendix B: Table B1; Appendix E: Fig. E2).

Previous experimental studies have found that the activity and survivorship of both predatory and coprophagous beetles primarily depended on water content or soil moisture (e.g., Dickinson et al. 1981). Low moisture decreased the activity and survival of the predators in our study, as suggested by the negative relationship between dung water content and the number of prey beetles (Appendix E: Fig. E3a, b). This would decrease dung loss rates, because dung loss increased with increasing abundance of the coprophagous beetle (Appendix E: Fig. E3). In theory, the probability of survival of the beetles should nonlinearly decrease with decreasing dung water content, with the survival probability declining to zero under a certain water content level. This seemed consistent with the second experiment of this study. For example, the regression relationships between water content and the number of prey beetles were not significant when the water content was too low or high, except for some cases in which the range of coprophagous beetle abundance was too narrow (Appendix E: Fig. E3a,b). The regression relationships between water content and dung loss also disappeared when the variation in the number of beetles or in water content was very small (Appendix E: Fig. E3c, d). If a very low water content occurred 
even only once in the warmed chambers during the course of the first experiment (as on the 20th day in the second experiment), mortality of coprophagous beetles would result in the difference in abundance of living prey beetles being minor among the warmed treatments.

It is worthwhile to note that the temperature effect on primary productivity was not as strong as on dung loss rates, as shown by the change in the strength of the indirect predator effect on plant growth. An increased loss rate in any particular predator treatment was usually accompanied by a corresponding increase in primary productivity, particularly in the unwarmed chambers. However, the dung loss rates were almost equal among the different warmed treatments, whereas plant biomass significantly differed among the treatments. This is possibly because dung nutrient release was not proportional to dung loss. Because only dissolved nutrients can be released into soil, a small rainfall event in the early dates might have caused a high nutrient release into soil, whereas in the late experimental stage, nutrients were hardly released from the dried dung pats in the warmed chambers (Appendix F). Another potential mechanism is that elevated temperature might have amplified the response of plant growth to soil nutrient differences in the warmed chambers. As noted, the climate of the study area is characterized by low temperature, and plant growth is generally limited by low temperature, as demonstrated by the results of warming experiments conducted in comparable alpine meadows (e.g., Klein et al. 2004). Increased plant production due to increased temperature might have confounded the indirect effect from dung loss rates. Moreover, because the relatively high temperature slowed the dung nutrient release, plant growth was more likely to be limited in the warmed chambers. As a result, a small increase in nutrient release rate may have been magnified in primary productivity in the warmed chambers. However, probably because of complicated interactions between plant and soil, the variation patterns did not consistently match each other between soil nutrient content and plant biomass (Fig. 2).

\section{Concluding remarks}

Biologists have long recognized that predators play an important role in structuring ecological communities and can have cascading effects on ecosystem functioning (Hairston et al. 1960, Oksanen et al. 1981, Fretwell 1987, Stiling 1999). However, it is also clear that top-down control by predators is highly variable in magnitude and direction and hence it is hard to predict the ecosystem consequence of the control (Oksanen and Oksanen 2000, Bruno and Cardinale 2008). Although some have predicted that trophic cascades are not significant in terrestrial, invertebrate-dominated, detritus food webs (Schmitz et al. 2000, Borer et al. 2005, Shurin et al. 2006), we herein demonstrate a strong trophic cascade in an alpine meadow, even though it is highly temperature dependent. This cascading effect on decomposition should be widespread in different ecosystems, because beetles are widespread and dominate decomposers in communities all around the world (Nichols et al. 2008). At least in grazing systems that occupy a significant fraction of the world's ecosystems, dung loss rate and nutrient cycling are largely related to activities of coprophagous beetles and their predators. The next step is to further test how ubiquitous such trophic cascades are in detritus food webs.

Equally importantly, we demonstrated that predators of decomposers have a contrasting role in ecosystem functioning (e.g., primary production) compared with predators of herbivores in living food webs. This complicates the prediction of the consequence of predator losses on ecosystem functioning, particularly when global warming is considered. On the one hand, a single predator species, if it occupies the same trophic level in both living and detritus food webs, can have opposite effects on a given ecosystem functioning, such as primary productivity. Although previous studies have emphasized the importance of omnivorous consumers feeding at different trophic levels (Bruno and O'Connor 2005), little attention has been paid to species functional differences between living and detritus food webs. On the other hand, within a biological community, trophic levels may respond differently to environmental change in (primary and secondary) productivity and the sensitivity of species loss, thereby increasing the uncertainty of predicting the ecosystem response to global warming. For example, in our study system, because predators are more likely to be lost under climate change and other human disturbances (Duffy 2002, Voigt et al. 2003), we would predict that warming would facilitate plant growth according to the "brownworld" role of the predators in decomposer communities. In addition, studies have predicted and demonstrated that primary production is increased by experimental warming in alpine or subalpine areas (e.g., Arft et al. 1999, Kudo and Suzuki 2003). However, the current study suggests that the increasing tendency could be cancelled and even reversed by the opposing effect of warming on decomposition and nutrient cycling in dung food webs. The warming effect on detritus food webs, as well as the associated ecosystem consequence of predator loss, should be fully studied and incorporated to improve the understanding of ecosystem functioning in a future warmed world.

In addition, although we did not directly address soil food webs, it is worthwhile to note that the "brownworld effect" of decomposer predators is of potentially high significance to soil carbon fluxes. Most soil food webs are detritus based; they may share common features with the dung food webs in our study, although the cascading effect was insignificant in one published case study (Mikola and Setälä 1998). If so, predators at similar trophic levels in soil food webs could be regulating the rate of soil carbon decomposition via their cascading effects on herbivores in the soil food 
web. In such a case, it may be predicted that soil $\mathrm{CO}_{2}$ release would be accelerated, provided that predator abundance declines with global warming and that soil carbon storage is very large (Lal 2008). This necessitates the protection of predator diversity in detritus food webs, as suggested by accumulating evidence from living food webs that multiple predator interactions can buffer the effects of climate warming (Wilmers and Getz 2005, Wilmers and Post 2006). Our study suggests that the research avenue regarding the role of predators in soil carbon fluxes should also be opened.

\section{ACKNOWLEDGMENTS}

We thank Xianming Gao, Yibin Yuan, Jian Feng, Guongyong $\mathrm{Li}$, Yinzhan Liu, and Junpeng $\mathrm{Mu}$ for field assistance, and Nico Eisenhauer for helpful comments on the manuscript. This study was funded by the Action-plan for West Development (KZCX2-XB2-02) and "100-Talent Program" of the Chinese Academy of Sciences.

\section{Literature Cited}

Allison, S. D. 2006. Brown ground: a soil carbon analogue for the green world hypothesis? American Naturalist 167:619627.

Arft, A. M., et al. 1999. Responses of tundra plants to experimental warming: meta-analysis of the international tundra experiment. Ecological Monographs 69:491-511.

Barton, B. T., and O. J. Schmitz. 2009. Experimental warming transforms multiple predator effects in a grassland food web. Ecology Letters 12:1-9.

Bishop, A. L., H. J. McKenzie, L. J. Spohr, and I. M. Barchia. 2005. Interactions between dung beetles (Coleoptera: Scarabaeidae) and the arbovirus vector Culicoides brevitarsis Kieffer (Diptera: Ceratopogonidae). Australian Journal of Entomology 44:89-96.

Borer, E. T., E. W. Seabloom, J. B. Shurin, K. E. Anderson, C. A. Blanchette, B. Broitman, S. D. Cooper, and B. S. Halpern. 2005. What determines the strength of a trophic cascade? Ecology 86:528-537.

Bornemissza, G. F. 1970. Insectary studies on the control of dung breeding flies by the activity of the dung beetle, Onthophagus gazella F. (Coleoptera: Scarabaeinae). Australian Journal of Entomology 9:31-41.

Brown, J. H., J. F. Gillooly, A. P. Allen, V. M. Savage, and G. B. West. 2004. Toward a metabolic theory of ecology. Ecology 85:1771-1789.

Bruno, J. F., and B. J. Cardinale. 2008. Cascading effects of predator richness. Frontiers in Ecology and the Environment 6:539-546.

Bruno, J. F., and M. I. O'Connor. 2005. Cascading effects of predator diversity and omnivory in a marine food web. Ecology Letters 8:1048-1056.

Byrnes, J., J. J. Stachowicz, K. M. Hultgren, A. R. Hughes, S. V. Olyarnik, and C. S. Thornber. 2006. Predator diversity strengthens trophic cascades in kelp forests by modifying herbivore behavior. Ecology Letters 9:61-71.

Cebrian, J. 2004. Role of first-order consumers in ecosystem carbon flow. Ecology Letters 7:232-240.

De Ruiter, P. C., A. M. Neutel, and J. C. Moore. 1995. Energetics, patterns of interaction strengths, and stability in real ecosystems. Science 269:1257-1260.

Dickinson, C. H., V. S. H. Underhay, and V. Ross. 1981. Effect of season, soil fauna and water content on the decomposition of cattle dung pats. New Phytologist 88:129-141.

Doube, B. M. 1990. A functional classification for analysis of the structure of dung beetle assemblages. Ecological Entomology 15:371-383.
Duffy, J. E. 2002. Biodiversity and ecosystem function: the consumer connection. Oikos 99:201-219.

Duffy, J. E., B. J. Cardinale, K. E. France, P. B. McIntyre, E. Thébault, and M. Loreau. 2007. The functional role of biodiversity in food webs: incorporating trophic complexity. Ecology Letters 10:522-538.

Duffy, J. E., J. P. Richardson, and K. E. France. 2005. Ecosystem consequences of diversity depend on food chain length in estuarine vegetation. Ecology Letters 8:301-309.

Dyer, L. A., and D. Letourneau. 2003. Top-down and bottomup diversity cascades in detrital vs. living food webs. Ecology Letters 6:60-68.

Emmerson, M. T., M. Bezemer, M. D. Hunter, and T. H. Jones. 2005. Global change alters the stability of food webs. Global Change Biology 11:490-501.

Emmerson, M. T., M. Bezemer, M. D. Hunter, T. H. Jones, G. J. Masters, and N. M. Van Dam. 2004. How does global change affect the strength of trophic interactions? Basic and Applied Ecology 5:505-514.

Feehan, J., R. D. Hughes, M. A. Bryce, and S. Runko. 1985. Bushfly abundance and population events in relation to dung beetle catches on the south coast of New South Wales. Australian Journal of Entomology 24:37-43.

Finke, D. L., and R. F. Denno. 2004. Predator diversity dampens trophic cascades. Nature 429:407-410.

Fretwell, S. D. 1987. Food chain dynamics: the central theory of ecology? Oikos 50:291-301.

Hairston, N. G., F. E. Smith, and L. B. Slobodkin. 1960. Community structure, population control, and competition. American Naturalist 94:421-425.

Halpern, B. S., K. Cottenie, and B. R. Broitman. 2006. Strong top-down control in Southern California kelp forest ecosystems. Science 312:1230-1232.

Holter, P. 1982. Resource utilization and local coexistence in a guild of Scarabaeid dung beetles (Aphodius spp.). Oikos 39:213-227.

Holter, P., and C. H. Scholtz. 2007. What do dung beetles eat? Ecological Entomology 32:690-697.

Hooper, D. U., et al. 2005. Effects of biodiversity on ecosystem functioning: a consensus of current knowledge. Ecological Monographs 75:3-35.

Houghton, J. T., Y. Ding, D. J. Griggs, M. Noguer, P. J. Van der Linden, X. Dai, K. Maskell, and C. A. Johnson. 2001. Climate change 2001: the scientific basis. Cambridge University Press, Cambridge, UK.

Ives, A. R., B. J. Cardinale, and W. E. Snyder. 2005. A synthesis of subdisciplines: predator-prey interactions, and biodiversity and ecosystem functioning. Ecology Letters 8:102-116.

Kishi, D., M. Murakami, S. Nakano, and K. Maekawa. 2005. Water temperature determines strength of top-down control in a stream food web. Freshwater Biology 50:1315-1322.

Kleiber, M. 1932. Body size and metabolism. Hilgardia 6:315353.

Klein, J. A., J. Harte, and X. Q. Zhao. 2004. Experimental warming causes large and rapid species loss, dampened by simulated grazing, on the Tibetan Plateau. Ecology Letters $7: 1170-1179$.

Krumins, J. A., Z. T. Long, C. F. Steiner, and P. J. Morin. 2006. Indirect effects of food web diversity and productivity on bacterial community function and composition. Functional Ecology 20:514-521.

Kudo, G., and S. Suzuki. 2003. Warming effects on growth, production, and vegetation structure of alpine shrubs: a fiveyear experiment in northern Japan. Oecologia 135:280-287.

Lal, R. 2008. Sequestration of atmospheric $\mathrm{CO}_{2}$ in global carbon pools. Energy and Environmental Science 1:86-100.

Letourneau, D. K., J. A. Jedlicka, S. G. Bothwell, and C. R. Moreno. 2009. Effects of natural enemy biodiversity on the suppression of arthropod herbivores in terrestrial ecosystems. 
Annual Review of Ecology, Evolution, and Systematics 40:573-592.

Lindeman, R. L. 1942. The trophic-dynamic aspect of ecology. Ecology 23:399-417.

Losey, J. E., and R. F. Denno. 1998. Positive predatorpredator interactions: enhanced predation rates and synergistic suppression of aphid populations. Ecology 79:21432152.

Lussenhop, J., R. Kumar, and J. E. Lloyd. 1986. Nutrient regeneration by fly larvae in cattle dung. Oikos 47:233-238.

Lussenhop, J., R. Kumar, D. T. Wicklow, and J. E. Lloyd. 1980. Insect effects on bacteria and fungi in cattle dung. Oikos 34:54-58.

McCann, K. S., J. B. Rasmussen, and J. Umbanhowar. 2005. The dynamics of spatially coupled food webs. Ecology Letters 8:513-523.

Mikola, J., and H. Setälä. 1998. No evidence of trophic cascades in an experimental microbial-based food web. Ecology 79:153-164.

Mohr, C. O. 1943. Cattle droppings as ecological units. Ecological Monographs 13:275-298.

Moore, J. C., E. L. Berlow, D. C. Coleman, P. C. De Ruiter, Q. Dong, A. Hastings, N. C. Johnson, K. S. McCann, K. Melville, and P. J. Morin. 2004. Detritus, trophic dynamics and biodiversity. Ecology Letters 7:584-600.

Moore, J. C., K. McCann, H. Setälä, and P. C. De Ruiter. 2003. Top down is bottom up: does predation in the rhizosphere regulate aboveground dynamics? Ecology 84:846-857.

Nichols, E., S. Spector, J. Louzada, T. Larsen, S. Amezquita, and M. E. Favila. 2008. Ecological functions and ecosystem services provided by Scarabaeinae dung beetles. Biological Conservation 141:1461-1474.

O'Connor, M. I., M. Piehler, D. Leech, A. Anton, and J. Bruno. 2009. Warming and resource availability shift food web structure and metabolism. PLoS Biology 7(8). [doi: 10. 1371/journal.pbio.1000178]

Odum, E. P. 1969. The strategy of ecosystem development. Science 164:262-270.

Oksanen, L., S. D. Fretwell, J. Arruda, and P. Niemela. 1981. Exploitation ecosystems in gradients of primary productivity. American Naturalist 118:240-261.

Oksanen, L., and T. Oksanen. 2000. The logic and realism of the hypothesis of exploitation ecosystems. American Naturalist 155:703-723.

Paine, R. T. 2002. Trophic control of production in a rocky intertidal community. Science 296:736-739.

Peñuelas, J., and I. Filella. 2001. Responses to a warming world. Science 294:793-794.

Preisser, E. L., and D. R. Strong. 2004. Climate affects predator control of an herbivore outbreak. American Naturalist 163:754-762.

Ridsdill-Smith, T. J., L. Hayles, and M. J. Palmer. 1986. Competition between the bush fly and a dung beetle in dung of differing characteristics. Entomologia Experimentalis et Applicata 41:83-90.

Root, T. L., J. T. Price, K. R. Hall, S. H. Schneider, C. Rosenzweig, and J. A. Pounds. 2003. Fingerprints of global warming on wild animals and plants. Nature 421:57-60.

Rosenheim, J. A. 2007. Intraguild predation: new theoretical and empirical perspectives. Ecology 88:2679-2680.

Rosenheim, J. A., D. D. Limburg, and R. G. Colfer. 1999. Impact of generalist predators on a biological control agent, Chrysoperla carnea: direct observations. Ecological Applications 9:409-417.

Sanford, E. 1999. Regulation of keystone predation by small changes in ocean temperature. Science 283:2095-2097.

Schaller, A. 2008. Induced plant resistance to herbivory. Springer-Verlag, Berlin, Germany.

Schmitz, O. J. 2003. Top predator control of plant biodiversity and productivity in an old-field ecosystem. Ecology Letters 6:156-163.
Schmitz, O. J. 2008. Effects of predator hunting mode on grassland ecosystem function. Science 319:952-954.

Schmitz, O. J. 2009. Effects of predator functional diversity on grassland ecosystem function. Ecology 90:2339-2345.

Schmitz, O. J., P. A. Hamback, and A. P. Beckerman. 2000. Trophic cascades in terrestrial systems: a review of the effects of carnivore removal on plants. American Naturalist 155:141-153.

Shurin, J. B., E. T. Borer, E. W. Seabloom, K. Anderson, C. A. Blanchette, B. Broitman, S. D. Cooper, and B. S. Halpern. 2002. A cross-ecosystem comparison of the strength of trophic cascades. Ecology Letters 5:785-791.

Shurin, J.-B., D. S. Gruner, and H. Hillebrand. 2006. All wet or dried up? Real differences between aquatic and terrestrial food webs. Proceedings of the Royal Society of London B 273:1-9.

Sih, A., G. Englund, and D. Wooster. 1998. Emergent impacts of multiple predators on prey. Trends in Ecology and Evolution 13:350-355.

Sinclair, A. R. E., S. Mduma, and J. S. Brashares. 2003. Patterns of predation in a diverse predator-prey system. Nature 425:288-290.

Solomon, S., D. Qin, M. Manning, Z. Chen, M. Marquis, K. B. Averyt, M. Tignor, and H. L. Miller. 2007. Climate change 2007: the physical science basis contribution of Working Group I to the Fourth Assessment Report of the Intergovernmental Panel on Climate Change. Cambridge University Press, New York, New York, USA.

Soluk, D. A., and N. C. Collins. 1988. Synergistic interactions between fish and stoneflies: facilitation and interference among stream predators. Oikos 52:94-100.

Srivastava, D. S., B. J. Cardinale, A. L. Downing, J. E. Duffy, C. Jouseau, M. Sankaran, and J. P. Wright. 2009. Diversity has stronger top-down than bottom-up effects on decomposition. Ecology 90:1073-1083.

Stiling, P. 1999. Ecology, theories and applications. Prentice Hall, Englewood Cliffs, New Jersey, USA.

Tilman, D. 1999. The ecological consequences of changes in biodiversity: a search for general principles. Ecology 80:1455-1474.

Trussell, G. C., and M. O. Nicklin. 2002. Cue sensitivity, inducible defense, and trade-offs in a marine snail. Ecology $83: 1635-1647$.

Tylianakis, J. M., R. K. Didham, J. Bascompte, and D. A. Wardle. 2008. Global change and species interactions in terrestrial ecosystems. Ecology Letters 11:1351-1363.

Voigt, W., J. Perner, A. J. Davis, T. Eggers, J. Schumacher, R. Bahrmann, B. Fabian, W. Heinrich, G. Kohler, D. Lichter, R. Marstaller, and F. W. Sander. 2003. Trophic levels are differentially sensitive to climate. Ecology 84:2444-2453.

Walker, M. D., W. A. Gould, and F. S. Chapin. 2001. Scenarios of biodiversity changes in arctic and alpine tundra. Pages 8399 in F. S. Chapin, O. E. Sala, and E. Huber-Sannwald, editors. Global biodiversity in a changing environment: scenarios for the 21st century. Springer-Verlag, New York, New York, USA.

Wardle, D. A. 2002. Communities and ecosystems: linking the aboveground and belowground components. Princeton University Press, Princeton, New Jersey, USA.

Wardle, D. A. 2006. The influence of biotic interactions on soil biodiversity. Ecology Letters 9:870-886.

Wardle, D. A., G. W. Yeates, W. M. Williamson, K. I. Bonner, and G. M. Barker. 2004. Linking aboveground and belowground communities: the indirect influence of aphid species identity and diversity on a three trophic level soil food web. Oikos 107:283-294.

Wilmers, C. C., and W. M. Getz. 2005. Gray wolves as climate change buffers in Yellowstone. PLoS Biology 3:571-576.

Wilmers, C. C., and E. Post. 2006. Predicting the influence of wolf-provided carrion on scavenger community dynamics 
under climate change scenarios. Global Change Biology 12:403-409.

Wilmers, C. C., E. Post, and A. Hastings. 2007. The anatomy of predator-prey dynamics in a changing climate. Journal of Animal Ecology 76:1037-1044.
Wu, X., and S. Sun. 2010. The roles of beetles and flies in yak dung removal in an alpine meadow of eastern QinghaiTibetan Plateau. Ecoscience 17:146-155.

Yamada, D., O. Imura, K. Shi, and T. Shibuya. 2007. Effect of tunneler dung beetles on cattle dung decomposition, soil nutrients and herbage growth. Grassland Science 53:121-129.

\section{APPENDIX A}

Variation in daily average temperature and relative humidity during the experiments (Ecological Archives M081-012-A1).

\section{APPENDIX B}

Results of three-way ANOVAs and regression analyses of the accessory experiment (Ecological Archives M081-012-A2).

\section{APPENDIX C}

Dung loss rates at the end of the ancillary experiment (Ecological Archives M081-012-A3).

\section{APPENDIX D}

Variation in number of large predators and small predators during the accessory experiment (Ecological Archives M081-012-A4).

\section{APPENDIX E}

Abundances of Aphodius erraticus larvae, dung water content, and the relationships between water content, dung loss rates, and the number of within-dung A. erraticus of the accessory experiment (Ecological Archives M081-012-A5).

\section{APPENDIX F}

Water content of the residual dung for different treatments at the end of the major experiment (Ecological Archives M081-012A6). 